\title{
The proteasome inhibitor, bortezomib, induces prostate cancer cell death by suppressing the expression of prostate-specific membrane antigen, as well as androgen receptor
}

\author{
KENJI KURODA ${ }^{1}$ and HE LIU ${ }^{2}$ \\ ${ }^{1}$ Department of Urology, National Defense Medical College, Tokorozawa, Saitama 359-8513, Japan; \\ ${ }^{2}$ Laboratory of Urological Oncology, Department of Urology, Weill Cornell Medical College, New York, NY 10065, USA
}

Received September 26, 2018; Accepted January 17, 2019

DOI: $10.3892 /$ ijo.2019.4706

\begin{abstract}
The progression of primary prostate cancer (PC) is dependent on the androgen receptor $(\mathrm{AR})$ and prostate-specific membrane antigen (PSMA). Furthermore, the growth of PC cells is terminated with the downregulation of both AR and PSMA. In our preliminary experiments, it was also found that bortezomib (BZ; PS-341) that inhibits 26S proteasome activity, acts as a downregulator of both PSMA and AR. In addition to evaluating the effects of $\mathrm{BZ}$ on protein expression, the present study evaluated and compared the anticancer effects of BZ on the growth of cells treated with BZ, docetaxel (DOC), or a combination of both. Western blot analysis was used to examine the expression levels of AR and PSMA. The knockdown effect of small interfering RNA (siRNA) and the drugs on the expression of either AR or PSMA was also evaluated. An MTT assay was performed in order to evaluate the inhibitory effects of the drugs on PC cells. The cell cycles were analyzed, and apoptotic cells were detected. The downregulation of AR and PSMA was observed using siRNA specific to AR or PSMA, and the inhibition of PSMA, as well as that of AR severely suppressed the growth of PC cells. The inhibitory effect of BZ alone on PSMA expression was similar to that of both AR- and PSMA-specific siRNA, and this drug also induced the downregulation of AR and PSMA in PC cells. This phenomenon was confirmed even in cells transfected to overexpress PSMA. The apoptosis-promoting effect of BZ on the cells was similar to that observed with BZ plus DOC, and more potent than that of DOC alone. BZ had the same inhibitory effect on the expression of AR and PSMA as did siRNA specific to AR or PSMA. On the whole, the findings of this study indicate that BZ may prove to be a promising
\end{abstract}

Correspondence to: Dr Kenji Kuroda, Department of Urology, National Defense Medical College, 3-2 Namiki, Tokorozawa, Saitama 359-8513, Japan

E-mail:kksmy@sa2.so-net.ne.jp

Key words: bortezomib, androgen receptor, prostate-specific membrane antigen, prostate cancer chemotherapeutic agent and may be used as a molecularly targeted drug in the treatment of PC.

\section{Introduction}

The growth of primary prostate cancer (PC) is dependent on androgens (1). Androgen ablation therapy through chemical castration with a luteinizing hormone-releasing hormone agonist, in combination with non-steroidal androgen receptor (AR) antagonists, is often used to impede the growth of PC (2,3). Although there is an initial regression in cancer growth, PC almost always progresses to a more aggressive castration-resistant form, which can be accompanied by the appearance of bone metastases (4).

A tumor biomarker of PC, i.e., prostate-specific membrane antigen (PSMA), is expressed in primary carcinomas and an increase in PSMA expression has been shown to be associated with tumor grade, pathological stage and aneuploidy (5). PSMA expression is also upregulated with the transition from androgen-sensitive PC to castration-refractory PC (6). Since PSMA is predominantly expressed in the prostate epithelium and the neovasculature of solid tumors $(7,8)$, it can be an excellent candidate in PSMA-targeted therapy.

Bortezomib (BZ; PS-341) is a boronic acid dipeptide that inhibits $26 \mathrm{~S}$ proteasome activity (9). The antitumor effects of BZ have been extensively studied in multiple myeloma (MM) cells. BZ has been shown to inhibit the proliferation of and induce the apoptosis of MM cells in vitro, and in an $\mathrm{MM}$ murine model via the inactivation of nuclear factor- $\kappa \mathrm{B}(\mathrm{NF}-\kappa \mathrm{B})(10-13)$. BZ has also been shown to overcome drug resistance and potentiate the anticancer effects of conventional therapeutic agents (14-16). Moreover, a previous clinical study using BZ in individuals with relapsed, refractory MM have demonstrated objective responses, some of which were complete responses (17). Although BZ appears to be a promising therapeutic agent for $\mathrm{MM}$, its activity against non-hematological malignancies, including PC remains to be elucidated, regardless of its potent anticancer effects on MM cells.

The results of our preliminary experiments to evaluate the effects of BZ treatment on PC cells suggested that BZ exerts an inhibitory effect on PSMA expression (data not shown). 
Therefore, the detailed functions of BZ in PC cells should be defined. It was previously observed that docetaxel (DOC) exerts a suppressive effect on AR expression, but not on PSMA expression (18). Thus, distinguishing between the effects of $\mathrm{DOC}$ and $\mathrm{BZ}$ on protein expression is an intriguing line of investigation.

In this study, we examined the effects of $\mathrm{BZ}$ on protein expression in PC cells and compared its anticancer effects on the growth of PC cells treated with BZ, DOC, or a combination of both.

\section{Materials and methods}

Cell lines and reagents. The human PC cell lines, LNCaP, CWR22Rv1, MDA-PCa-2b and LAPC-4, were purchased from the American Type Culture Collection (ATCC, Manassas, VA, USA). The LNCaP and CWR22Rv1 cells were maintained in RPMI-1640 medium supplemented with $2 \mathrm{mM} \mathrm{L-glutamine,}$ $1 \%$ penicillin-streptomycin, and $10 \%$ heat-inactivated fetal bovine serum (FBS) (all from Invitrogen/Thermo Fisher Scientific, Waltham, MA, USA). The MDA-PCa- $2 b$ cells were grown in $\mathrm{F} 12 \mathrm{~K}$ medium containing $2 \mathrm{mM} \mathrm{L}$-glutamine, $1 \%$ penicillin-streptomycin, 20\% heat-inactivated FBS, $25 \mathrm{ng} / \mathrm{ml}$ cholera toxin (Sigma-Aldrich, St. Louis, MO, USA), $10 \mathrm{ng} / \mathrm{ml}$ epidermal growth factor (BD Biosciences, Franklin Lakes, NJ, USA), $5 \mu \mathrm{M}$ phosphoethanolamine, $100 \mathrm{pg} / \mathrm{ml}$ hydrocortisone, $45 \mathrm{nM}$ selenious acid and $5 \mu \mathrm{g} / \mathrm{ml}$ insulin (all from Sigma-Aldrich). The LAPC-4 cells were maintained in IMDM medium supplemented with $2 \mathrm{mM} \mathrm{L}$-glutamine, $1 \%$ penicillin-streptomycin and $5 \%$ heat-inactivated FBS. All the cell lines were kept at $37^{\circ} \mathrm{C}$ in a $5 \% \mathrm{CO}_{2}$ atmosphere. DOC was purchased from Sanofi-Aventis (Bridgewater, NJ, USA). BZ was purchased from Tronto Research Chemicals (North York, ON, Canada).

RNA interference. Small interfering RNA (siRNA) duplexes specific to AR and PSMA and random siRNA were purchased from Dharmacon (Lafayette, CO, USA). The sequence of AR-specific siRNA (AR-siRNA) corresponds to the human AR site was 5'-GACUCAGCUGCCCCAUCCA-3') (19). The PSMA-specific siRNA (PSMA-siRNA) is a custom product (siGENOME Duplex D-005881-04-0050, Human FOLH1, NM_004476). A non-targeting siRNA (NT-siRNA) (5'-CCU ACGCCACCAAUUUCGU-3') was used as a control for the RNA interference experiments (20). Following overnight incubation of the suspended cells at $37^{\circ} \mathrm{C}$ transfected with $10-40 \mathrm{nM}$ of AR- or PSMA-siRNA or NT-siRNA using Lipofectamine RNAiMAX reagent (Invitrogen/Thermo Fisher Scientific) according to the manufacturer's instructions, the media were changed with fresh media and the cells were incubated at $37^{\circ} \mathrm{C}$ with or without the drugs for the time indicated in the Figures and Figure legends.

Cell cycle analysis. All cell lines were first incubated in 6-well plates $\left(2.5 \times 10^{5}\right.$ cells/well $)$ overnight and then transfected with $10 \mathrm{nM}$ of AR-siRNA and/or $10 \mathrm{nM}$ of PSMA-siRNA for $72 \mathrm{~h}$. Subsequently, the cells were prepared for cell cycle analysis using the Cell Cycle Phase Determination kit (Cayman Chemical Co., Ann Arbor, MI, USA) according to the manufacturer's instructions. Briefly, the cells were trypsinized, collected and centrifuged to the pellet. The cell pellet was fixed in fixative included in the kit for at least $2 \mathrm{~h}$ at $-20^{\circ} \mathrm{C}$ prior to propidium iodide (PI) staining after being washed 2 times with assay buffer also in the kit. After the fixed cells were centrifuged at $500 \mathrm{xg}$ for $5 \mathrm{~min}$ and the fixative was thoroughly removed, the cell pellet was suspended in PI solution and incubated for $30 \mathrm{~min}$ at room temperature in the dark. The samples were subjected to FACScan flow cytometer and analyzed using CellQuest software (both from BD Biosciences).

Western blotanalysis. The cells were lysed with Cell Lysis Buffer (Cell Signaling Technology, Danvers, MA, USA) containing $1 \mathrm{mM}$ phenylmethylsulphonyl fluoride (EMD Chemicals, Gibbstown, NJ, USA). Equal amounts of proteins (40-60 $\mu \mathrm{g}$ for each) determined by the Lowry method (DC protein assay reagents) were applied to each well on a $10 \%$ Tris- $\mathrm{HCl}$ gel (both from Bio-Rad Laboratories, Hercules, CA, USA). The proteins were transferred onto Immobilon-P Membranes (Millipore, Billerica, MA, USA), after which the filters were washed with $15 \mathrm{ml}$ of Tris-buffered saline (Bio-Rad Laboratories) with Tween-20 (TBST) containing 5\% bovine serum albumin (Sigma-Aldrich) 3 times for 5 min each at room temperature, and probed with solutions containing the following reagents: Mouse monoclonal anti-PSMA antibody J591 (generated and purified in Dr Neil Bander's laboratory) (dilution 1:4,000) (8), mouse monoclonal antibody anti-AR (sc-7305) (Santa Cruz Biotechnology, Santa Cruz, CA, USA) (dilution 1:100), goat polyclonal antibody anti-glyceraldehyde-3-phosphate dehydrogenase (sc-31915) (GAPDH; Santa Cruz Biotechnology) (dilution 1:100). The temperature and duration of the incubation with the primary and secondary antibodies were $4^{\circ} \mathrm{C}$ overnight, and room temperature for $1 \mathrm{~h}$, respectively. After these steps, proteins were detected using ECL Plus Western blotting detection reagents (GE Healthcare, Chicago, IL, USA).

$A R$ and PSMA DNA transfection. For all transfections, the LNCaP, CWR22Rv1 and MDA-PCa-2b cells were seeded at $2 \times 10^{5}$ cells/well in $1 \mathrm{ml}$ of complete media in 12-well plates or $3.5 \times 10^{5}$ cells/well in $2 \mathrm{ml}$ of complete media in 6-well plates on the day before transfection. Subsequently, $1.3 \mu \mathrm{g}$ (for 12-well) or $3.4 \mu \mathrm{g}$ (for 6-well) of AR DNA, or $1.0 \mu \mathrm{g}$ (for 12-well) or $2.5 \mu \mathrm{g}$ (for 6-well) of PSMA DNA were mixed with $1 \mu \mathrm{l}$ (for 12-well) or $2.5 \mu 1$ (for 6-well) of PLUS reagent (Invitrogen/Thermo Fisher Scientific) in $200 \mu \mathrm{l}$ (for 12-well) or $500 \mu \mathrm{l}$ (for 6-well) of serum-free media (Opti-MEM ${ }^{\circledR}$ I Reduced Serum Media; Invitrogen/Thermo Fisher Scientific) for $10 \mathrm{~min}$. A total of $4 \mu \mathrm{l}$ (for 12-well) or $11.25 \mu \mathrm{l}$ (for 6-well) of Lipofectamine LTX (Invitrogen/Thermo Fisher Scientific) was then added, mixed and incubated for an additional $25 \mathrm{~min}$ before the mixture of DNA, PLUS reagent and Lipofectamine LTX was added dropwise to the cells. The cells were then incubated for $48 \mathrm{~h}$ at $37^{\circ} \mathrm{C}, 5 \% \mathrm{CO}_{2}$ prior to the addition of $10 \mathrm{nM}$ of DOC to the cells transfected with AR DNA or $20 \mathrm{nM}$ of BZ to the cells transfected with PSMA DNA. Following treatment with DOC or BZ for an additional $48 \mathrm{~h}$, the cells in the 12-well plates were subjected to cell counting by flow cytometry, and those in the 6-well plates were subjected to western blot analysis.

For cell counting, the cells were first incubated overnight in 24-well plates $\left(4 \times 10^{4}\right.$ cells/well $)$ and then treated for various 
periods of times with several methods. The media from each well were then discarded. Subsequently, $300 \mu 1$ of $0.1 \%$ trypsin was placed in each well for $8 \mathrm{~min}$ at $37^{\circ} \mathrm{C}$ followed by $700 \mu \mathrm{l}$ of fresh media containing $10 \% \mathrm{FBS}$, and the cells were collected. A total of $50 \mu \mathrm{l}$ of SPHERO ${ }^{\mathrm{TM}}$ (Spherotech, Lake Forest, IL, USA) was then added to each sample, and the cells were then subjected to flow cytometry (BD Biosciences). The data were analyzed using CellQuest software (BD Biosciences) according to the manufacturer's instructions.

Cell viability assay. MTT assay was used to assess cell viability following treatment of the PC cells. The cells were seeded in 96 -well plates $\left(5 \times 10^{3}\right.$ cells/well), grown overnight, and then treated for various periods of time as indicated in the results and/or figure legends. Subsequently, $10 \mu \mathrm{l}$ of MTT reagent (R\&D Systems, Minneapolis, MN, USA) were added to each well. The plates were incubated for approximately $4 \mathrm{~h}$ at $37^{\circ} \mathrm{C}$. When purple precipitate was clearly visible grossly, $100 \mu \mathrm{l}$ of detergent reagent (R\&D Systems) was added to all wells, including the control wells. The color change was measured at $570 \mathrm{~nm}$ with a reference wavelength of $650 \mathrm{~nm}$ on a Spectramax 340PC Microplate Reader (Molecular Devices Corporation, Sunnyvale, CA, USA) following overnight incubation at room temperature.

Apoptotic cell detection. The LNCaP and CWR22Rv1 cells were seeded in 6-well plates (1x105/well), grown overnight, and then treated with $5 \mathrm{nM}$ of DOC and/or $10 \mathrm{nM}$ of BZ for $72 \mathrm{~h}$. Following treatment, the cells trypsinized were collected and centrifuged at $1,000 \mathrm{x}$ g for $5 \mathrm{~min}$ at room temperature, and then resuspended in $500 \mu \mathrm{l}$ of binding buffer (MBL International, Woburn, MA, USA). Subsequently, $5 \mu 1$ of Annexin V-conjugated fluorescein isothiocyanate (FITC) and $5 \mu \mathrm{l}$ of PI (both from MBL International) were added into each binding buffer containing the suspended cells. Following a 5-min incubation at room temperature in the dark, the cells were subjected to FACScan flow cytometer (BD Biosciences). The data were analyzed using CellQuest software (BD Biosciences) according to the manufacturer's instructions.

Statistical analysis. All values in bar graphs are expressed as the means \pm standard deviation, and variables for different groups were compared using one-way analysis of variance (ANOVA) with Tukey's post hoc test, and a value of $\mathrm{P}<0.05$ was considered to indicate a statistically significant difference. Statistical analyses were performed with JMP version 8.0 (SAS Institute, Cary, NC, USA).

\section{Results}

Effect of AR-and/or PSMA-siRNA on cell growth and protein expression. The knockdown effect of AR- or PSMA-siRNA transfection on cell growth and protein expression in the LNCaP and CWR22Rv1 cells was examined. The knockdown of both AR and PSMA suppressed cell growth more significantly $(33.89 \pm 5.42$ and $45.00 \pm 3.00 \%)$ than AR alone (50.50 \pm 4.36 and $56.92 \pm 1.81 \%)$ or PSMA alone $(57.21 \pm 2.43$ and $68.18 \pm 2.93 \%)$ in the LNCaP and CWR22Rv1 cells, respectively (Fig. 1A). There was also a significant difference in growth between the cells transfected with AR- or PSMA-siRNA or both and the untreated cells in the LNCaP and CWR22Rv1 cells (Fig. 1A). No statistically significant difference in cell grow th between the AR-siRNA-transfected cells and PSMA-siRNA-transfected cells was observed (Fig. 1A). The expression levels of AR and PSMA were sufficiently downregulated following the knockdown of AR or PSMA using siRNA specific to AR or PSMA (Fig. 1B and C).

Cellcycleanalysisincellstreated with AR-and/orPSMA-siRNA transfection. The percentage of sub-G1 in the cells transfected with AR-siRNA alone (20 nM), or PSMA-siRNA alone (20 nM), or AR-siRNA (10 nM) plus PSMA-siRNA (10 nM) for $72 \mathrm{~h}$ was $54.15,55.99$ and $70.98 \%$, respectively in the LNCaP cells, and $16.90,9.41$ and $39.52 \%$, respectively in the CWR22Rv1 cells (Fig. 2A and B).

Effect of DOC on protein expression in cells transfected with AR DNA and that of BZ on protein expression in those transfected with PSMA DNA. The effects of DOC on the LNCaP, CWR22Rv1 and MDA-PCa-2b cells, and on the cells transfected to highly express AR were examined. Even under the condition of AR upregulation, DOC inhibited the expression of AR, but not that of PSMA, in all of the cell lines tested (Fig. 3A). The effects of BZ were also examined using the same cell lines transfected with PSMA DNA. BZ decreased both AR and PSMA expression in normal cells and in the cells transfected to upregulate PSMA in every cell line tested (Fig. 3B).

Effect of DOC and/or BZ on the expression of AR and PSMA. The effects of DOC and/or BZ on the expression of proteins, including AR and PSMA in the LNCaP, CWR22rv1 and MDA-PCa-2b cells incubated with $10 \mathrm{nM}$ DOC, and/or $50 \mathrm{nM}$ $\mathrm{BZ}$ for $48 \mathrm{~h}$ were evaluated. DOC inhibited the expression of $\mathrm{AR}$ in all the cell lines tested in a dose-dependent manner; however, it did not suppress PSMA expression in any of the cell lines tested (Fig. 4). On the other hand, BZ inhibited the expression of both AR and PSMA expression in all the cell lines tested (Fig. 4).

Inhibitory effect of BZ and/or DOC on normal cells or those transfected to upregulate AR or PSMA. The inhibitory effects of BZ and/or DOC on normal cells or cells transfected to overexpress AR or PSMA were also evaluated. The results of MTT assay revealed that BZ itself exerted a significantly potent anticancer effect on the cell lines tested with or without the administration of DOC (Fig. 5). Cell growth was not inhibited compared to the normal cells in all the cell lines transfected to overexpress AR or PSMA, which were respectively treated with DOC or BZ (Fig. 6A and B).

Apoptotic cell detection in cells treated with BZ and/or $D O C$. The percentages of late apoptotic cells detected using Annexin $\mathrm{V}$ and propidium iodide staining, which were used with DOC alone $(5 \mathrm{nM}), \mathrm{BZ}$ alone $(10 \mathrm{nM})$, or DOC $(5 \mathrm{nM})$ plus BZ (10 nM) for $72 \mathrm{~h}$, were $37.84,52.67$ and $61.69 \%$, respectively in the LNCaP cells and 12.29, 37.59 and 49.87\%, respectively in the CWR22Rv1 cells (Fig. 7). 
A

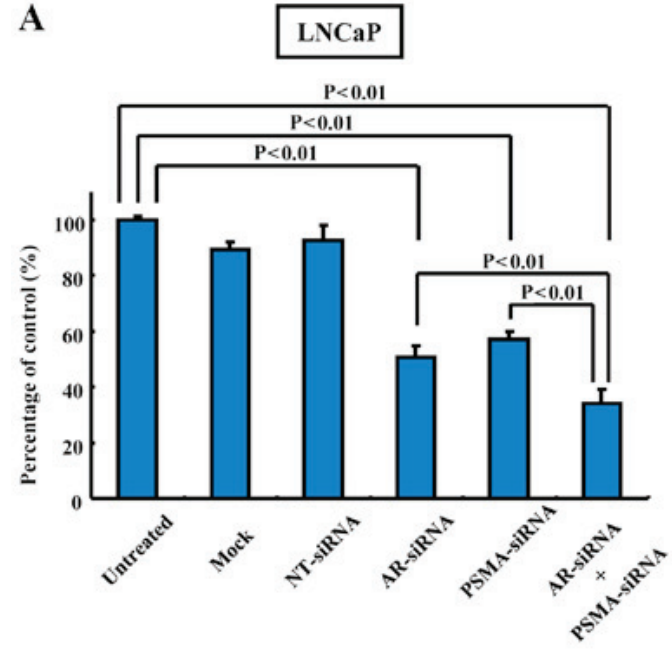

B

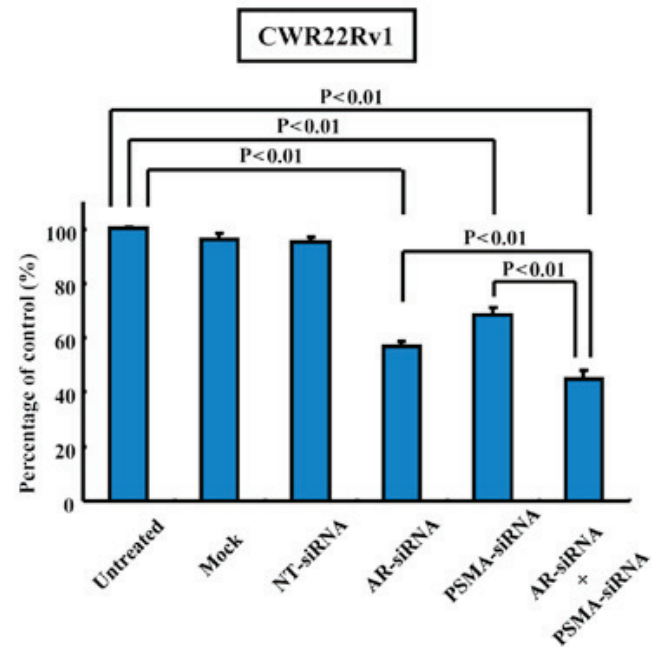

CWR22Rv1

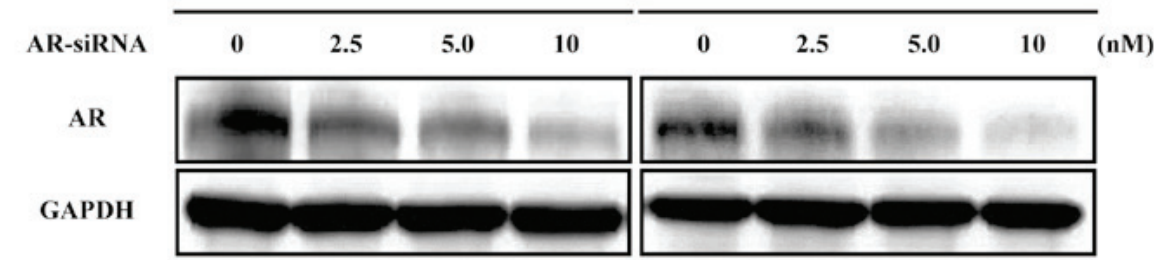

C

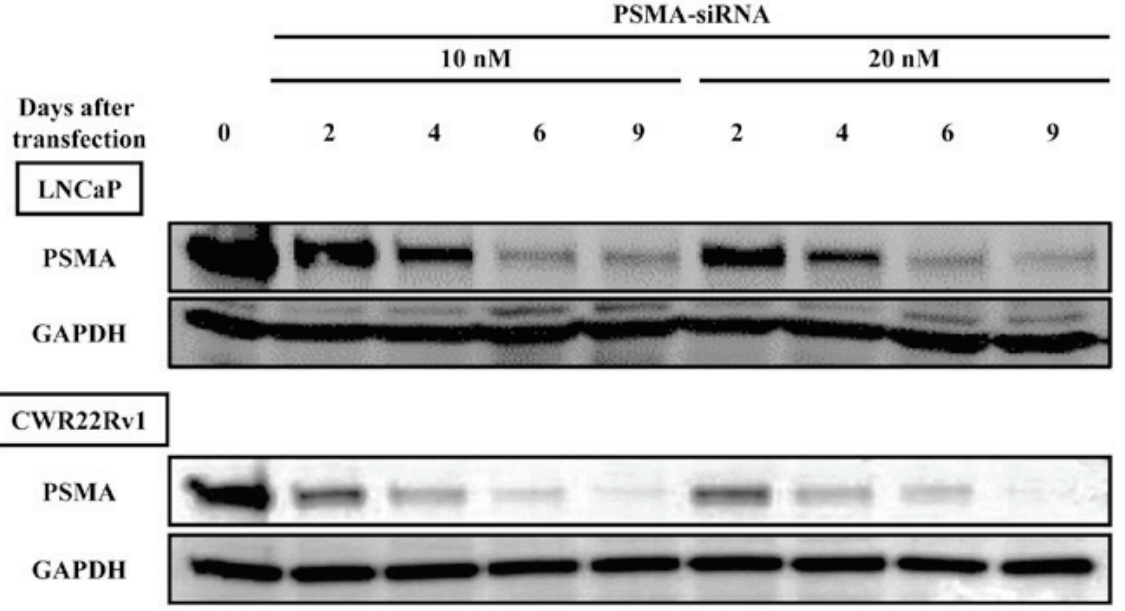

Figure 1. (A) Knockdown effect of both AR-siRNA (20 nM) or PSMA-siRNA (20 nM) for $72 \mathrm{~h}$ suppressed the growth of LNCaP and CWR22Rv1 cells more significantly than AR alone $(40 \mathrm{nM})$ or PSMA alone $(40 \mathrm{nM})(\mathrm{P}<0.01)$. (B) Knockdown effect of AR-siRNA on AR expression for $48 \mathrm{~h}$. (C) Knockdown effect of PSMA-siRNA on PSMA expression for 9 days. AR, androgen receptor; PSMA, prostate-specific membrane antigen.

\section{Discussion}

Previous research suggests that PSMA expression is modulated inversely by the expression level of androgens. In other words, PSMA expression is upregulated when AR expression is downregulated and vice versa $(6,21)$. It was previously confirmed that saporin-conjugated, anti-PSMA antibodies have potent and selective anticancer effects on PSMA-expressing PC cells in vitro and in vivo (22). The same effects were observed by immunohistochemistry in the downregulation of PSMA, particularly in inoculated tumors (22). These results indicate that along with decreased levels of PSMA, AR expression may be downregulated. Consequently, the viability of PC cells could be significantly reduced by the simultaneous knockdown of PSMA and AR. As stated in this study in the
Introduction, $\mathrm{BZ}$ was found to exert an inhibitory effect on PSMA expression in our preliminary experiments. The present study verified whether the anticancer effect of BZ is dependent on decreased expression levels of both AR and PSMA.

Based on these previous findings, this study investigated the anticancer effect of $\mathrm{BZ}$ on $\mathrm{PC}$ cell lines compared to DOC alone or BZ plus DOC after confirming the inhibitory effect of siRNA on cell growth, the expression of PSMA as well as AR, and the cell cycles (Figs. 1 and 2). The results suggested that the simultaneous knockdown of AR and PSMA exerted sufficient growth inhibitory effects on PC cells. These phenomena were tested and confirmed using the cells transfected to overexpress AR or PSMA to determine whether DOC exerts an inhibitory effect on AR expression or whether BZ exerts a suppressive effect on PSMA expression even in the cells transfected to 
A LNCaP

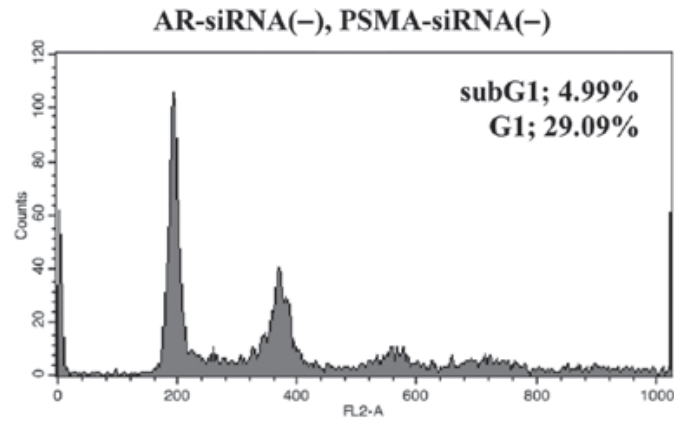

AR-siRNA(-), PSMA-siRNA $20 \mathrm{nM}$

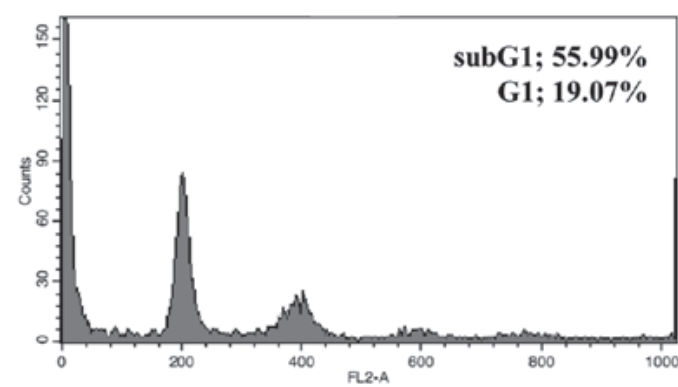

\section{B CWR22Rv1}
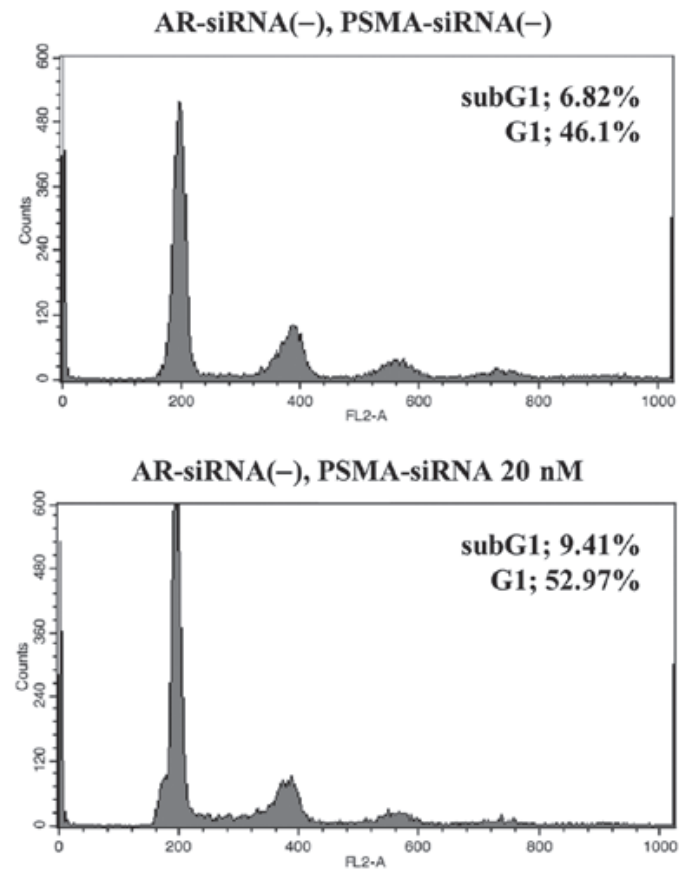
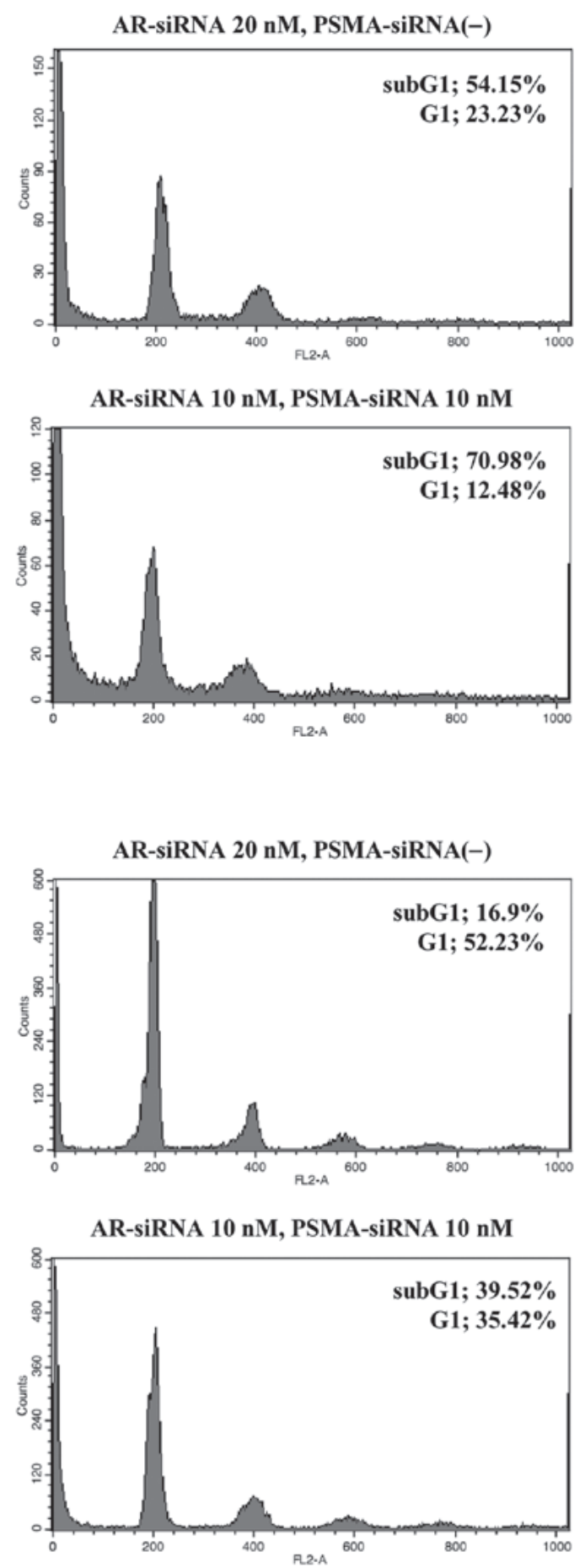

Figure 2. Percentage of sub-G1 cells were measured in cells transfected with AR-siRNA alone (20 nM), or PSMA-siRNA alone (20 nM), or AR-siRNA $(10 \mathrm{nM})$ plus PSMA-siRNA (10 nM) for $72 \mathrm{~h}$ in (A) LNCaP and (B) CWR22Rv1 cells. AR, androgen receptor; PSMA, prostate-specific membrane antigen.

upregulate AR or PSMA expression (Figs. 3 and 4). These findings were similar to those observed with both AR- and PSMA-siRNA on cell growth, protein expression and cell cycle analysis observed in Figs. 1 and 2. Based on these findings, a bona-fide inhibitory effect on cell growth in PC cells was examined. We do assert that BZ has an inhibitory effect on the expression of both AR and PSMA. However, the expression levels of AR and PSMA are inversely correlated. When AR expression is upregulated, PSMA expression is downregulated (6). Therefore, we did not use cell lines transfected with AR DNA for examining the effect of BZ on AR expression, as we suspected that PSMA expression would be relatively low in such cell lines with the effect of BZ not sufficiently significant. The effect of BZ alone on cell growth was found to be suf ficiently potent when compared to the effect of DOC alone or to that of the combined administration of both drugs on LNCaP and CWR22Rv1 cells. Furthermore, BZ inhibited the growth of the two cell lines in a dose-dependent 


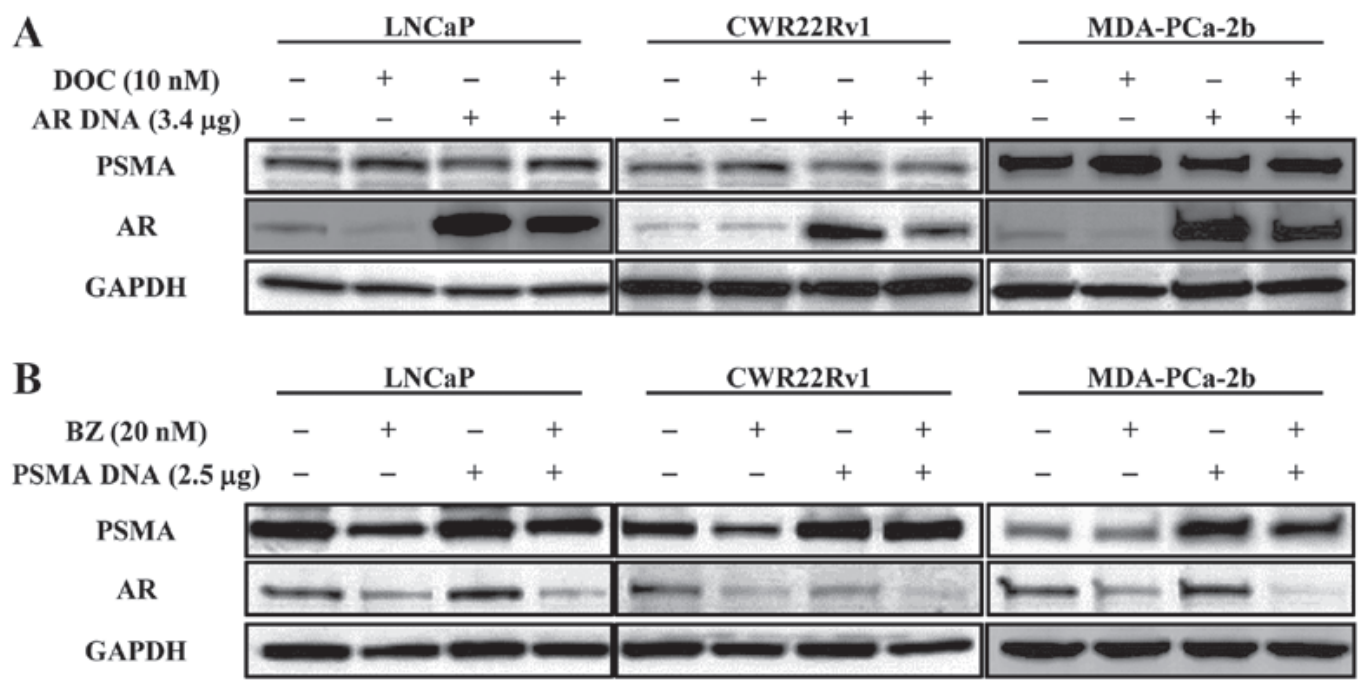

Figure 3. (A) LNCaP, CWR22Rv1 and MDA-PCa-2b cells were transfected with AR DNA ( $3.4 \mu \mathrm{g}$ ) for $48 \mathrm{~h}$, and then treated with DOC (10 $\mathrm{nM}$ ) for a further $48 \mathrm{~h}$. (B) The Same cell lines were transfected with PSMA DNA $(2.5 \mu \mathrm{g})$ for $48 \mathrm{~h}$, and then treated with BZ (20 nM) for a further $48 \mathrm{~h}$. Total protein was then analyzed by western blot analysis. AR, androgen receptor; PSMA, prostate-specific membrane antigen; DOC, docetaxel; BZ, bortezomib.

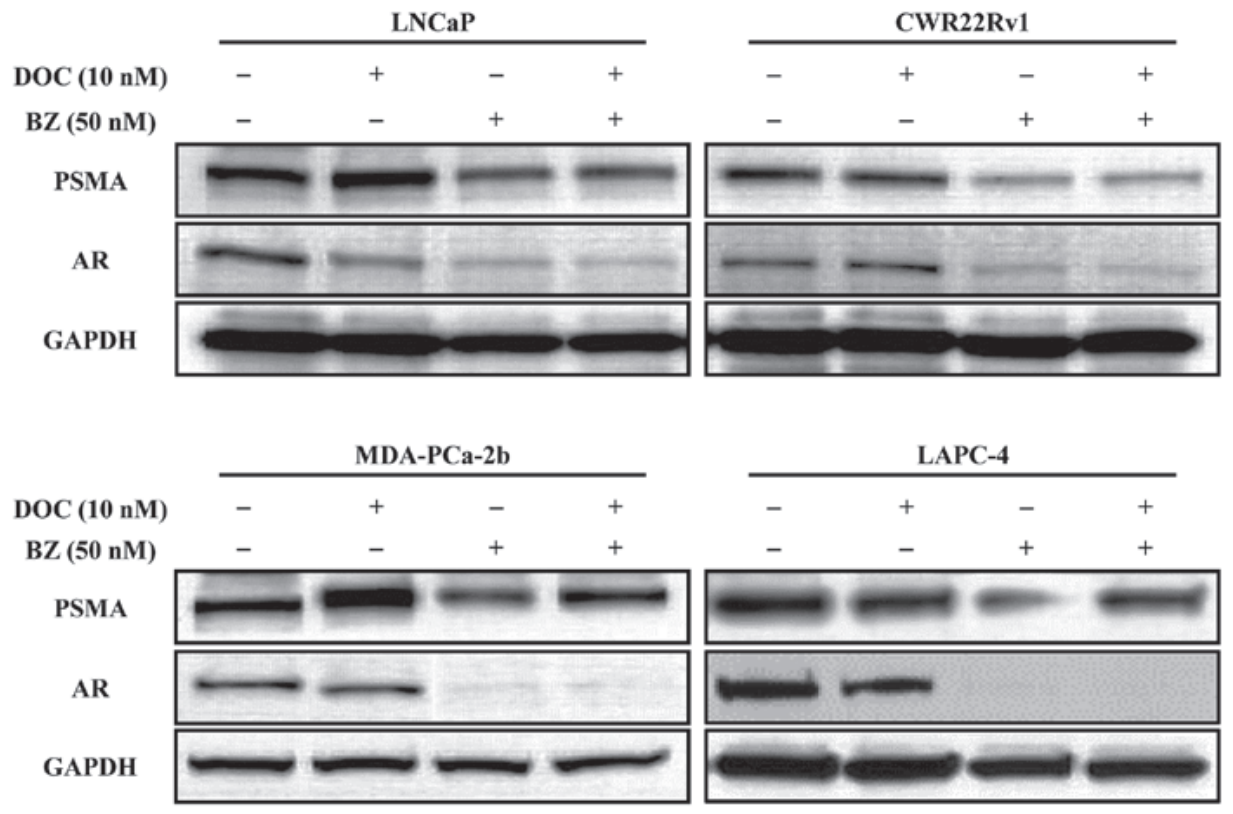

Figure 4. Effects of DOC, BZ, or both, on protein expression following 48-h treatment of the LNCaP, CWR22Rv1, MDA-PCa-2b and LAPC-4 cells confirmed by western blot analysis. AR, androgen receptor; PSMA, prostate-specific membrane antigen; DOC, docetaxel; BZ, bortezomib.

manner (Fig. 5). We believe that AR and PSMA play essential roles in enabling cells to survive the treatment of anticancer drugs, such as DOC and BZ (23-26). In fact, we demonstrated that cells transfected with AR DNA or PSMA DNA were resistant to the inhibitory effects of DOC and BZ on the growth of the cells (Fig. 6). In detecting apoptotic cells by fluorescence-activated cell sorting (FACS) analysis, the apoptosis-inducing effect on the cells treated with $\mathrm{BZ}$ alone was close to that observed with treatment with BZ plus DOC, but more potent than that observed with treatment with DOC alone (Fig. 7). The dose of BZ and DOC tested was designated appropriately in this series of experiments we conducted, and was within a normal limitation $(16,18)$. Based on these findings, BZ induced the apoptosis of the cells expressing AR, as well as PSMA by suppressing both the expression of both proteins, and the apoptosis-inducing effect of $\mathrm{BZ}$ was similar to that observed with DOC plus BZ.

BZ is a highly selective, reversible inhibitor of the $26 \mathrm{~S}$ proteasome that is recommended for single-agent use in the treatment of patients with multiple myeloma (9-13). BZ has been known to have a variety of mechanisms influencing the physiology of cells, which indicates that exposure to BZ has the exposure to BZ results in the stabilization of p21, p27 and $\mathrm{p} 53$, as well as the pro-apoptotic Bid and Bax proteins, caveolin- 1 and inhibitor $\kappa \mathrm{B}-\alpha$, which prevents the activation of NF- $\mathrm{KB}$-induced cell survival pathways. BZ can also promote the activation of proapoptotic c-Jun-NH2 terminal kinase, as well as the endoplasmic reticulum stress response. Thus, this drug exerts potent anticancer effects on various types of malignant tumors (27-29). 
A

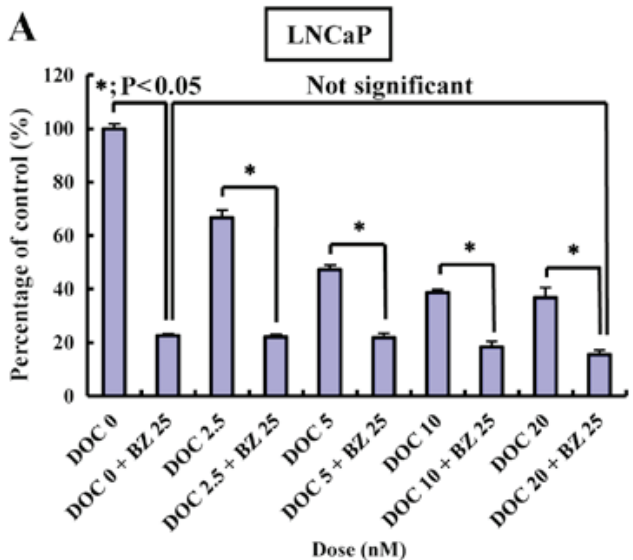

B
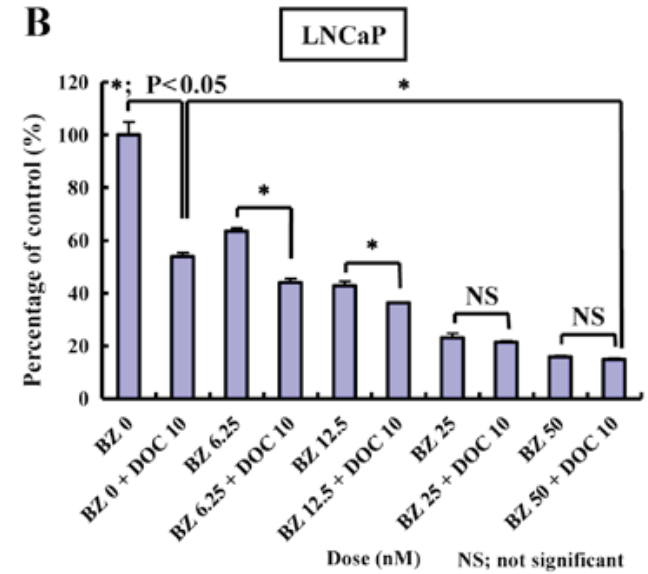

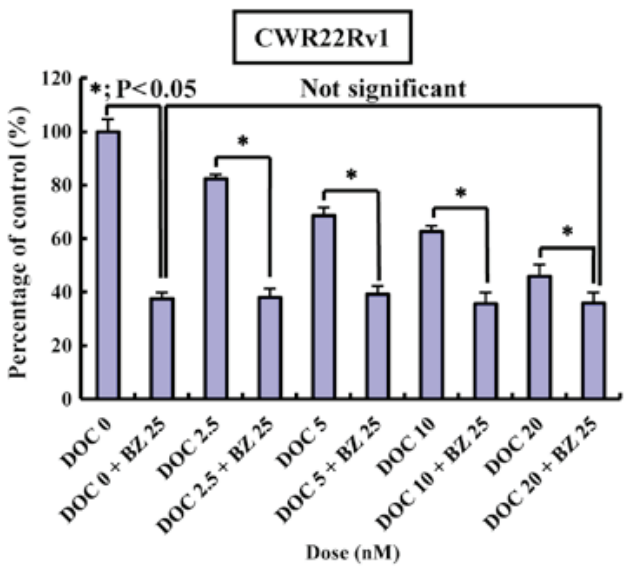

CWR22Rv1

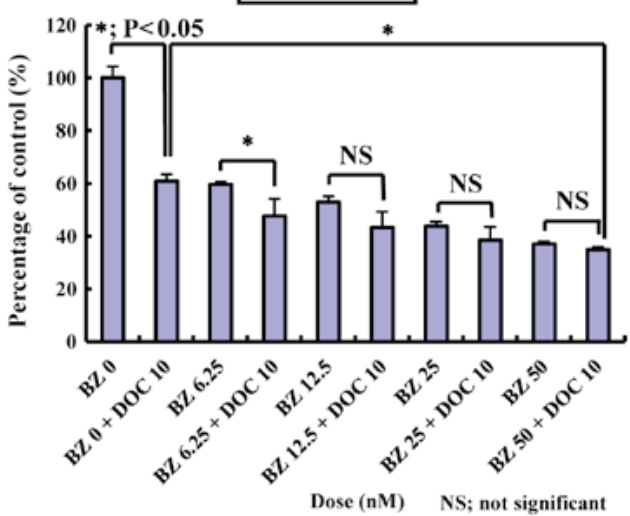

Figure 5. Results of MTT assay indicated the inhibition of the growth of LNCaP and CWR22Rv1 cells treated with several doses of (A) DOC and 25 nM of BZ or (B) those treated with several doses of BZ and $10 \mathrm{nM}$ of DOC for $48 \mathrm{~h}$. AR, androgen receptor; PSMA, prostate-specific membrane antigen; DOC, docetaxel; BZ, bortezomib.
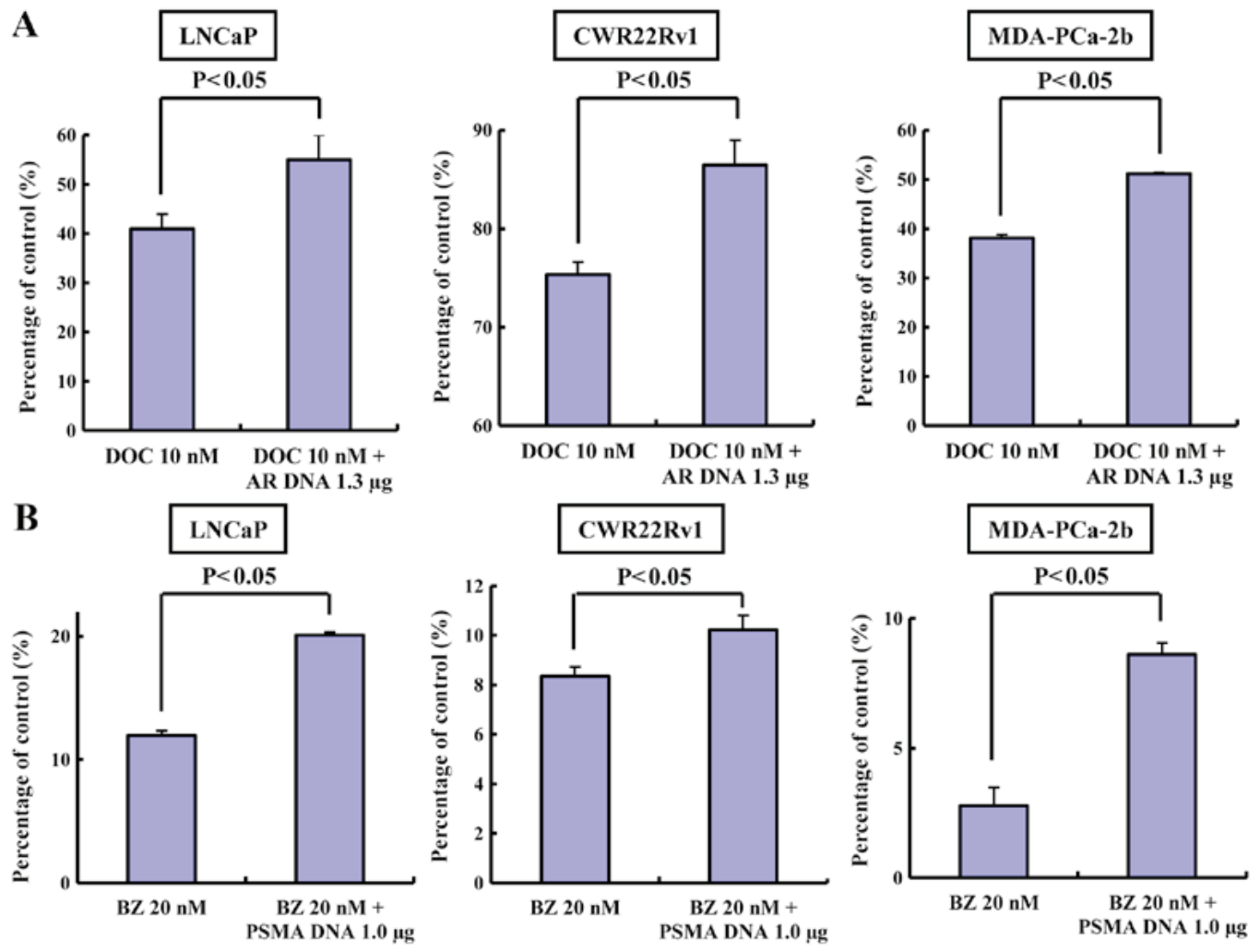

Figure 6. Cell counting by flow cytometry revealed that AR DNA and PSMA DNA increased chemoresistance to (A) DOC and (B) BZ, respectively, in LNCaP, CWR22Rv1, and MDA-PCa-2b cells. 

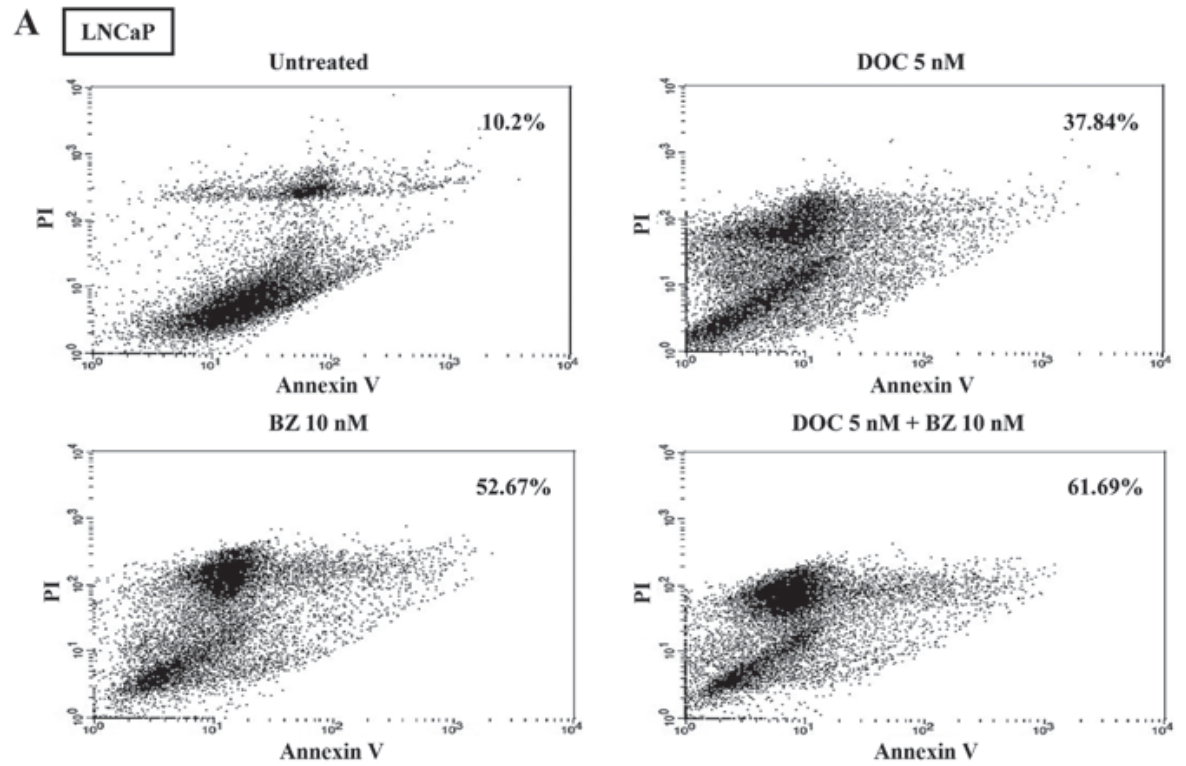

\section{B CWR22Rv1}
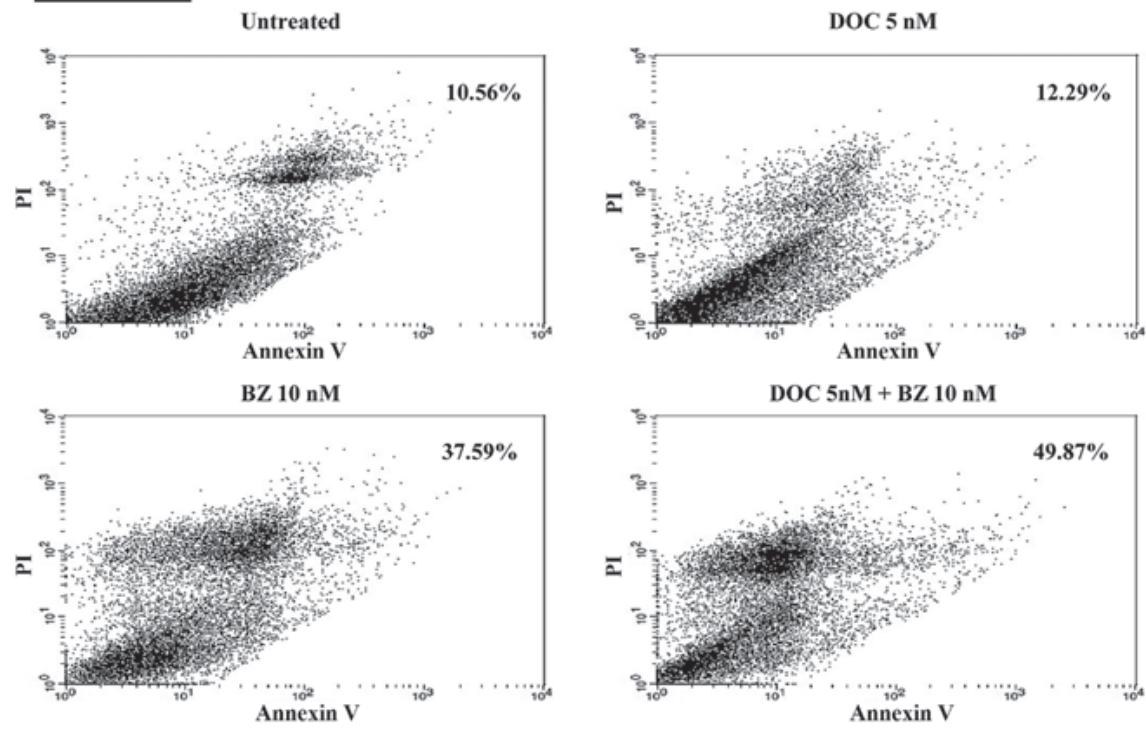

Figure 7. Percentage of late apoptotic cells detected using Annexin V and propidium iodide was determined in DOC-treated ( $5 \mathrm{nM})$ cells, BZ-treated (10 nM) cells, and cells treated with their combination for $72 \mathrm{~h}$ in (A) LNCaP cells and (B) CWR22Rv1 cells.

Although a relatively high expression level of p21 and p27 have been found in cells treated with BZ, other proteins such as $\mathrm{p} 53$, Bid, Bax and c-Jun-NH2 terminal kinase have been found to be expressed weakly even in the cells treated with BZ alone (data not shown). However, DOC has been known to be an effective chemotherapeutic drug against PC. As far as we investigated its anticancer function, this drug has an inhibitory effect on AR expression, not PSMA (18). Therefore, the anticancer effect of BZ may be attributed to its downregulating effect against both AR and PSMA.

Resistance to chemotherapy can be attributed to mechanisms specific to PC biology, general mechanisms common to other tumor types, drug pharmacokinetics, such as continued androgen-AR signaling and upregulation of pro-survival cellular pathways, or to the role of angiogenesis and immune mechanisms in the tumor microenvironment (30). Therefore, BZ should be used in combination with other anticancer agents. BZ has reportedly demonstrated anticancer effects when used in combination with other chemotherapeutic drugs, such as etoposide, for PC cell lines and has been reported to sensitize human PC cells to radiation effects when administered with DOC $(31,32)$. Other studies have reported the synergistic anticancer effects of $\mathrm{BZ}$ when it is administered in combination with various agents on PC cell lines $(33,34)$. In addition to PC, BZ has reportedly been shown to exert a synergistic anticancer effect on ovarian cancer and multiple myeloma when administered with a histone deacetylase inhibitor or daratumumab (a human CD38-directed monoclonal antibody) plus dexamethasone $(35,36)$. In the near future, BZ may be prescribed in combination with targeted molecular drugs or immune checkpoint inhibitors. Although a report indicating the single use of proteasome inhibitor exerting an anticancer effect in the treatment of PC exists (37), the fact that the use of $\mathrm{BZ}$ to prevent biochemical recurrence if used together with antiandrogen drugs introduced in another study should also be considered (38). Nevertheless, further research is still required to overcome these limitations. 
There are a few limitations to this study. First, the anticancer effect of BZ alone was found to be as close as that of BZ plus DOC. This reason for this may be that DOC occasionally exerts an upregulating effect on PSMA, which was not found previously, but DOC could theoretically induce the upregulation of PSMA by downregulating AR expression. Similar results to the ones found in the present study have been reported (39). In fact, further investigation includes whether the synergistic effect of BZ plus other anticancer drugs or chemical agents have a more potent effect on PC cells. Second, the mechanism of AR and PSMA downregulation induced by BZ was not described. Furthermore, we could not clarify why the expression of AR and PSMA were inversely correlated, but this phenomenon remained consistent from our previous study to the present study (18).

In conclusion, the results of this study suggest that the knockdown of PSMA expression, as well as the suppression of AR expression inhibits the growth of treated PC cells. BZ, which has the same effect on the expression of AR and PSMA, is promising if applied to clinical use for molecular targeted therapy. The inhibition of PSMA, as well as AR severely inhibits the growth of PC cells. The proteasome inhibitor, BZ, has the same inhibitory effect on the expression of AR and PSMA as siRNA specific to AR or PSMA. Our results from cells transfected with AR DNA or PSMA DNA would also be more relevant as BZ and/or DOC may be used for patients with aggressive PC. This chemotherapeutic agent shows promise as a molecularly targeted drug for the treatment of PC, and BZ plus other anticancer drugs or chemical agents may be required for more potent anticancer effect.

\section{Acknowledgements}

Not applicable.

\section{Funding}

This study was funded by a research grant from Weill Cornell Medical College.

\section{Availability of data and materials}

The datasets used and/or analyzed during the current study are available from the corresponding author on reasonable request.

\section{Authors' contributions}

$\mathrm{KK}$ and HL were involved in the conception and design of the study; KK performed the experiments; KK analyzed the data; KK drafted the manuscript; KK and HL reviewed and edited the manuscript. Both authors have read and approved the final manuscript.

\section{Ethics approval and consent to participate}

Not applicable.

\section{Patient consent for publication}

Not applicable.

\section{Competing interests}

The authors declare that they have no competing interests.

\section{References}

1. Huggins C and Hodges CV: Studies on prostatic cancer. I. The effect of castration, of estrogen and androgen injection on serum phosphatases in metastatic carcinoma of the prostate. CA Cancer J Clin 22: 232-240, 1972.

2. Brawer MK, Crawford ED, Labrie F, Mendoza-Valdes A, Miller PDPD and Petrylak DP: Androgen deprivation and other treatments for advanced prostate cancer. Rev Urol 3 (Suppl 2): S59-S68, 2001.

3. Labrie F: Medical castration with LHRH agonists: 25 years later with major benefits achieved on survival in prostate cancer. J Androl 25: 305-313, 2004

4. Feldman BJ and Feldman D: The development of androgen-independent prostate cancer. Nat Rev Cancer 1: 34-45, 2001.

5. Ross JS, Sheehan CE, Fisher HAG, Kaufman RP Jr, Kaur P, Gray K, Webb I, Gray GS, Mosher R and Kallakury BV: Correlation of primary tumor prostate-specific membrane antigen expression with disease recurrence in prostate cancer. Clin Cancer Res 9: 6357-6362, 2003.

6. Wright GL Jr, Grob BM, Haley C, Grossman K, Newhall K, Petrylak D, Troyer J, Konchuba A, Schellhammer PF and Moriarty R: Upregulation of prostate-specific membrane antigen after androgen-deprivation therapy. Urology 48: 326-334, 1996.

7. Chang SS, Keefe DS, Bacich DJ, Reuter VE, Heston WD and Gaudin PB: Advances in brief prostate-specific membrane antigen is produced in tumor. Clin Cancer Res 5: 2674-2681, 1999.

8. Liu H, Moy P, Kim S, Xia Y, Rajasekaran A, Navarro V, Knudsen B and Bander NH: Monoclonal antibodies to the extracellular domain of prostate-specific membrane antigen also react with tumor vascular endothelium. Cancer Res 57: 3629-3634, 1997.

9. Adams J: Proteasome inhibitors as new anticancer drugs. Curr Opin Oncol 14: 628-634, 2002.

10. LeBlanc R, Catley LP, Hideshima T, Lentzsch S, Mitsiades CS, Mitsiades N, Neuberg D, Goloubeva O, Pien CS, Adams J, et al: Proteasome inhibitor PS-341 inhibits human myeloma cell growth in vivo and prolongs survival in a murine model. Cancer Res 62: 4996-5000, 2002.

11. Hideshima T, Chauhan D, Richardson P, Mitsiades C, Mitsiades N, Hayashi T, Munshi N, Dang L, Castro A, Palombella V, et al: NF- $\kappa \mathrm{B}$ as a therapeutic target in multiple myeloma. J Biol Chem 277: 16639-16647, 2002.

12. Mitsiades N, Mitsiades CS, Poulaki V, Chauhan D, Fanourakis G, Gu X, Bailey C, Joseph M, Libermann TA, Treon SP, et al: Molecular sequelae of proteasome inhibition in human multiple myeloma cells. Proc Natl Acad Sci USA 99: 14374-14379, 2002.

13. Orlowski RZ, Stinchcombe TE, Mitchell BS, Shea TC, Baldwin AS, Stahl S, Adams J, Esseltine DL, Elliott PJ, Pien CS, et al: Phase I trial of the proteasome inhibitor PS-341 in patients with refractory hematologic malignancies. J Clin Oncol 20: 4420-4427, 2002.

14. Mitsiades N, Mitsiades CS, Richardson PG, Poulaki V, Tai YT, Chauhan D, Fanourakis G, Gu X, Bailey C, Joseph M, et al: The proteasome inhibitor PS-341 potentiates sensitivity of multiple myeloma cells to conventional chemotherapeutic agents: Therapeutic applications. Blood 101: 2377-2380, 2003

15. Ma MH, Yang HH, Parker K, Manyak S, Friedman JM, Altamirano C, Wu ZQ, Borad MJ, Frantzen M, Roussos E, et al: The proteasome inhibitor PS-341 markedly enhances sensitivity of multiple myeloma tumor cells to chemotherapeutic agents. Clin Cancer Res 9: 1136-1144, 2003.

16. Hideshima T, Richardson P, Chauhan D, Palombella VJ, Elliott PJ, Adams J and Anderson KC: The proteasome inhibitor PS-341 inhibits growth, induces apoptosis, and overcomes drug resistance in human multiple myeloma cells. Cancer Res 61: 3071-3076, 2001.

17. Richardson PG, Barlogie B, Berenson J, Singhal S, Jagannath S, Irwin D, Rajkumar SV, Srkalovic G, Alsina M, Alexanian R, et al: A phase 2 study of bortezomib in relapsed, refractory myeloma. N Engl J Med 348: 2609-2617, 2003. 
18. Kuroda K, Liu H, Kim S, Guo M, Navarro V and Bander NH: Docetaxel down-regulates the expression of androgen receptor and prostate-specific antigen but not prostate-specific membrane antigen in prostate cancer cell lines: Implications for PSA surrogacy. Prostate 69: 1579-1585, 2009.

19. Compagno D, Merle C, Morin A, Gilbert C, Mathieu JR, Bozec A Mauduit C, Benahmed $M$ and Cabon F: SIRNA-directed in vivo silencing of androgen receptor inhibits the growth of castration-resistant prostate carcinomas. PLoS One 2: e1006, 2007.

20. Lee UJ, Choung SR, Prakash KV, Lee EJ, Lee MY, Kim YJ, Han CW and Choi YC: Dual knockdown of p65 and p50 subunits of NF-kappaB by siRNA inhibits the induction of inflammatory cytokines and significantly enhance apoptosis in human primary synoviocytes treated with tumor necrosis factor-alpha. Mol Biol Rep 35: 291-298, 2008.

21. Israeli RS, Powell CT, Corr JG, Fair WR and Heston WD Expression of the prostate-specific membrane antigen. Cancer Res 54: 1807-1811, 1994.

22. Kuroda K, Liu H, Kim S, Guo M, Navarro V and Bander NH: Saporin toxin-conjugated monoclonal antibody targeting prostate-specific membrane antigen has potent anticancer activity. Prostate 70: 1286-1294, 2010.

23. Bravaccini S, Puccetti M, Bocchini M, Ravaioli S, Celli M, Scarpi E, De Giorgi U, Tumedei MM, Raulli G, Cardinale L, et al PSMA expression: A potential ally for the pathologist in prostate cancer diagnosis. Sci Rep 8: 4254, 2018.

24. Minner S, Wittmer C, Graefen M, Salomon G, Steuber T, Haese A, Huland H, Bokemeyer C, Yekebas E, Dierlamm J, et al: High level PSMA expression is associated with early PSA recurrence in surgically treated prostate cancer. Prostate 71: 281-288, 2011.

25. Khurana N, Talwar S, Chandra PK, Sharma P, Abdel-Mageed AB Mondal D and Sikka SC: Sulforaphane increases the efficacy of anti-androgens by rapidly decreasing androgen receptor levels in prostate cancer cells. Int J Oncol 49: 1609-1619, 2016.

26. Komura K, Jeong SH, Hinohara K, Qu F, Wang X, Hiraki M, Azuma H, Lee GS, Kantoff PW and Sweeney CJ: Resistance to docetaxel in prostate cancer is associated with androgen receptor activation and loss of KDM5D expression. Proc Natl Acad Sci USA 113: 6259-6264, 2016.

27. Williams S, Pettaway C, Song R, Papandreou C, Logothetis C and McConkey DJ: Differential effects of the proteasome inhibitor bortezomib on apoptosis and angiogenesis in human prostate tumor xenografts. Mol Cancer Ther 2: 835-843, 2003.

28. Papandreou CN and Logothetis CJ: Bortezomib as a potential treatment for prostate cancer. Cancer Res 64: 5036-5043, 2004.
29. Codony-Servat J, Tapia MA, Bosch M, Oliva C, DomingoDomenech J, Mellado B, Rolfe M, Ross JS, Gascon P, Rovira A, et al: Differential cellular and molecular effects of bortezomib, a proteasome inhibitor, in human breast cancer cells Mol Cancer Ther 5: 665-675, 2006.

30. Lohiya V, Aragon-Ching JB and Sonpavde G: Role of chemotherapy and mechanisms of resistance to chemotherapy in metastatic castration-resistant prostate cancer. Clin Med Insights Oncol 10 (Suppl 1): 57-66, 2016.

31. Aras B and Yerlikaya A: Bortezomib and etoposide combinations exert synergistic effects on the human prostate cancer cell line PC-3. Oncol Lett 11: 3179-3184, 2016.

32. Cao W, Shiverick KT, Namiki K, Sakai Y, Porvasnik S, Urbanek C and Rosser CJ: Docetaxel and bortezomib downregulate Bcl-2 and sensitize PC-3-Bcl-2 expressing prostate cancer cells to irradiation. World J Urol 26: 509-516, 2008.

33. Christian PA, Thorpe JA and Schwarze SR: Velcade sensitizes prostate cancer cells to TRAIL induced apoptosis and suppresses tumor growth in vivo. Cancer Biol Ther 8: 73-80, 2009.

34. Thorpe JA, Christian PA and Schwarze SR: Proteasome inhibition blocks caspase- 8 degradation and sensitizes prostate cancer cells to death receptor-mediated apoptosis. Prostate 68: 200-209, 2008

35. Janyst K, Janyst M, Siernicka M and Lasek W: Synergistic antitumor effects of histone deacetylase inhibitor scriptaid and bortezomib against ovarian cancer cells. Oncol Rep 39: 1999-2005, 2018

36. Iida S, Ichinohe T, Shinagawa A, Suzuki K, Takezako N and Aoki M: Safety and efficacy of daratumumab in combination with bortezomib and dexamethasone in Japanese patients with relapsed or refractory multiple myeloma. Int J Hematol 107: 460-467, 2018.

37. Wehenkel M, Ban JO, Ho YK, Carmony KC, Hong JT and Kim KB: A selective inhibitor of the immunoproteasome subunit LMP2 induces apoptosis in PC-3 cells and suppresses tumour growth in nude mice. Br J Cancer 107: 53-62, 2012.

38. Kraft AS, Garrett-Mayer E, Wahlquist AE, Golshayan A, Chen CS, Butler W, Bearden J and Lilly M: Combination therapy of recurrent prostate cancer with the proteasome inhibitor bortezomib plus hormone blockade. Cancer Biol Ther 12: 119-124, 2011.

39. Hainsworth JD, Meluch AA, Spigel DR, Barton J Jr, Simons L, Meng C, Gould B and Greco FA: Weekly docetaxel and bortezomib as first-line treatment for patients with hormone-refractory prostate cancer: A Minnie Pearl Cancer Research Network phase II trial. Clin Genitourin Cancer 5: 278-283, 2007. 